\title{
NUMERICAL ANALYSIS OF HYDRAULIC PARAMETERS OF WATER SUPPLY SYSTEM BY APPLICATION OF "SPLINE" INTERPOLATION
}

\author{
Jasmin Hrnjadović ${ }^{1}$ \\ Jasmin Hrnjadović
Anadel Galamić \\ Mufid Tokić ${ }^{3}$
}

UDK: 519.6:628.1

DOI: 10.14415/konferencijaGFS2019.074

Summary: The water supply system is a planned and meaningfully connected set of facilities and activities aimed at ensuring sufficient quantity of water in the most economical way.

Defining the functional dependence of the hydraulic parameters of the water supply system is crucial because it enables the calculation of unknown values based on the appropriate available or measurable values.

„Spline“ interpolation is one of the methods by which it is possible approximately, but with sufficient accuracy, to define the functional dependence of hydraulic parameters if we have known values at certain characteristic intervals that can be measured or calculated by one of the numerical methods. "Spline" interpolation denotes the method of constructing a function within the range of a discrete set, which approximates the already known points. The result is a function, or set of functions, by which it is possible to calculate the value of an unknown function for any value of the variable at a defined interval. The specific application of this method will be shown on the example in this paper.

Keywords: water supply system, spline interpolation, hydraulic parameters, function

\section{INTRODUCTION}

In hydrotechnical practice, we often encounter the impossibility of an explicit statement of a particular problem using some of the previously well-known and established patterns. The reason for this is usually many unknowns that significantly affect the value of the unknown size we are looking for. The water supply system is a complex system that, depending on the conditions of population and the specificity of water consumption in the function of time, can have many unknowns that sometimes can hardly be expressed in a single sense. For example, water losses in the water supply system are often an important

\footnotetext{
${ }^{1}$ Jasmin Hrnjadović, MSc. C. E., Faculty of Mining, Geology and Civil Engineering, Tuzla , Bosnia and Herzegovina, tel: +387 65496 689, e-mail: jasmin.hrnjadovic@gmail.com

${ }^{2}$ Anadel Galamić, MSc. C. E

${ }^{3}$ Mufid Tokić, MSc. C. E.,
} 
problem for every water supply system. It is caused by the durability of pipelines or supporting structures in the system, poor quality construction or illegal connections to the water supply system. These are mostly values that are difficult to express and define numerically, but they can be measured on-site, and based on performed measurements define their dependence on certain influencing factors. The aim of this paper is to find a mathematical form that can numerically express a certain undefined problem in hydrotechnics and to determine unknown sizes based on available or measurable data. One of the mathematical tools for solving this problem is the application of spline interpolation, which makes it possible to define the functional dependence of individual parameters in order to obtain an unknown function value for any value of the variable.

\section{INTERPOLATION IN HYDROTECHNICS}

Interpolation in numerical mathematics denotes the method of constructing new points within the range of a discrete set of known points. Interpolation can be applied in engineering to solve many problems, when by sampling or by experimental measurement we can obtain function values for certain values of the variable. Spline interpolation is one of the methods by which it is possible to construct a function that approximately corresponds to known points of a set obtained by measurement, or by some of the known numerical methods. The construction of a curve that passes through already known points is called curve adjustment or regression analysis. "Spline" interpolation is a specific case of curve adjustment in which the curve must flow exactly to known data points.

With good properties, the interpolation polynomial has flaws. One of them is that the increase in the number of measurements increases the degree of polynomial. Spline interpolation resolves this problem so that instead of one polynomial of a large degree, more polynomials of lower degree are used. The application of the cubic spline, shown in this paper, is obtained by associating the two neighboring points with the third-degree curve. Different polynomials of the third degree are used here at each interval and polynomial segments with "smooth" interconnections are adopted.

Cubic spline has the most common application in interpolation, primarily for two reasons. The first is that the third level of the function is relatively low, so the invoices are not too complex. The second is that this level is high enough to describe many engineering problems. The curve of the third-degree polynomial, as a rule, has growth and decay areas, a local minimum and a local maximum and an inflection point. These properties of cubic functions are important in engineering practice because they enable the establishment of a relationship between two dependent variables for different cases:

- $\quad$ when increasing the value of one size, the value of another increases or decreases;

- $\quad$ value of the first size at which the second achieves the smallest, ie the highest value (in an interval);

- $\quad$ value of the first size where the value of the second size passes from accelerated growth to slowed (slow growth in the accelerated, accelerated fall in the slow or slowdown in the accelerated).

In general, for $n$ given points $\left(x_{1}, y_{1}\right),\left(x_{2}, y_{2}\right), \ldots\left(x_{n}, y_{n}\right)$ we calculate $n$ cubic functions $f_{1}(x)$, $f_{2}(x), \ldots, f_{n}(x)$, satisfying the following conditions: 
Contemporary achievements in civil engineering 23-24. April 2019. Subotica, SERBIA

a) The first cubic function passes through the first and second points, the second passes through the second and third, etc., while the last function passes through the penultimate and last point. This means that, overall, cubic splines will go through all the points.

b) Neighboring cubic functions in the common point have the same first derivatives - this means that there is a tangent to the curve of the cubic spline.

c) Neighboring cubic functions in the common point have equal second derivatives - this means that there are acceleration at the points of interpolation.

d) The spline is uniquely determined. If there is no additional information, it is considered that these are natural conditions: $f_{1}{ }^{\prime \prime}\left(x_{1}\right)=0$ i $f_{n}{ }^{\prime \prime}\left(x_{n}\right)=0$ [9].

In hydrotechnics, there is often a problem that certain values of hydraulic parameters (flow, pressure, flow rate, etc.) can not be accurately calculated or measured under certain conditions. Sometimes it is possible to get these data, but in certain circumstances (at certain time or space intervals), by using some of the known numerical methods or by direct or indirect measurement. Values between known points can be defined using spline interpolation, where the functional dependence of individual parameters is defined, so that for any value of the variable $x$ it is possible to calculate the value of $y$.

Below is the application of this method in one section of the pressure pipeline of the water supply system. The mutual dependence of the manometric height (pressure in the pipe) and the diameter of the pipeline is established for the defined conditions. The aim of the research is to make a comparative analysis of explicitly defined functions (based on known forms in hydraulics) and "spline" functions, and to examine their possible coincidence.

\section{EXPLICITLY EXPRESSED DEPENDENCE OF HYDRAULIC PARAMETERS}

As a basis of research and analysis, it was adopted a section of the pressure pipeline of the water supply system, of settlements which currently inhabits about 3000 inhabitants.

There is a newly built water supply system in the settlement, which is designed to get water from an already existing $500 \mathrm{~m}^{3}$ tank, which is an integral part of the water supply system of the neighboring settlement. Covered water is pumped through the pumping stations on several angles with three-stage pumping, from which the gravitational supply of distribution lines is envisaged [1].

The number of inhabitants at the end of the planning period or after n-years is defined:

$$
S_{b}=S_{p}\left(1+\frac{k_{p}}{100}\right)^{n}
$$

$S_{p}$ - number of inhabitants at the beginning of the planning period

$k_{p}$ - population growth rate (in our case $1.0 \%$ )

$n$ - number of years of the planning period [5]

Based on the calculated number of inhabitants at the end of the planning period, the average daily water consumption is calculated as follows [8]: 
Савремена достигнућа у грађевинарству 23-24. април 2019. Суботица, СРБИЈА

$$
Q_{s r}=q_{s p} \cdot S_{b}
$$

$\mathrm{q}_{\mathrm{sp}}$ - specific water consumption (l/inh/day)

$\mathrm{S}_{\mathrm{b}}$ - number of inhabitants

The maximum daily water consumption is calculated as follows:

$$
Q_{\max , d n}=Q_{s r} \cdot k_{d}
$$

while maximum hourly consumption is calculated as follows:

$$
Q_{\max , h}=Q_{s r} \cdot k_{d} \cdot k_{h}
$$

$k_{d}$ - coefficient of daily nonsingularity

$k_{h}$ - coefficient of hourly nonsingularity

The pressure pipeline is dimensioned based on the maximum daily water consumption obtained according to formula (3). The first section of the pressure pipeline, which is the subject of the analysis, is a total length of $4455 \mathrm{~m}$, the height difference between the beginning and the end of the section (geodetic height) is $66.10 \mathrm{~m}$, and it flows $13.0 \mathrm{l}$ / s of water [1].

The total loss of pressure is calculated according to the form [2]:

$$
\Delta H=\lambda \cdot \frac{L}{D} \cdot \frac{v^{2}}{2 g}+\Sigma \xi \cdot \frac{v^{2}}{2 g}
$$

Since, in the case of long pipe lines, local losses are negligibly small compared to linear, the previous pattern takes the form [3]:

$$
\Delta H=\lambda \cdot \frac{L}{D} \cdot \frac{v^{2}}{2 g}=\lambda \cdot \frac{L}{D} \cdot \frac{Q^{2}}{2 g A^{2}}=0,0826 \cdot \lambda \cdot \frac{L}{D^{5}} \cdot Q^{2}
$$

Therefore, the total manometric height represents the sum of the geodetic height and all the losses on the considered section [4]:

$$
H=H_{g}+\Delta H \text {, }
$$

from where, it is obtained the final form for the value of the manometric height in the function of the pipe diameter by adding constant values: 
Contemporary achievements in civil engineering 23-24. April 2019. Subotica, SERBIA

$$
\mathrm{H}=66,10+0,00124 \cdot \mathrm{D}^{-5}
$$

Based on the defined function (8), for any value of pipe diameter it is possible to calculate the total manometric height on the basis of which is adopted the required power of pumping aggregates for the transport of water [7].

\section{SPLINE INTERPOLATION OF FUNCTION $H=f(D)$}

In order to define spline functions at an interval, it is necessary to define some of known points at the considered interval. In this case, the variable is the diameter of the pipeline $D$, while the value of the function is the total manometric height $H$. If we assume some values of the variable, i.e. the usual pipe diameters, and based on the expression (8) we define the value of the function for the given known values of the variable, we obtain the data shown in Table 1.

Table 1: Dependence of the manometric height and pipe diameter

\begin{tabular}{|c|c|c|}
\hline $\begin{array}{c}\text { Rated pipe diameter } \\
\text { DN }\end{array}$ & $\begin{array}{c}\text { Internal diameter } \\
\mathbf{D}(\mathbf{m m})\end{array}$ & $\begin{array}{c}\text { Manometric heigh } \\
\text { H (m) }\end{array}$ \\
\hline 110 & 96,8 & 212,44 \\
\hline 160 & 141,0 & 88,41 \\
\hline 200 & 176,2 & 73,42 \\
\hline 250 & 220,4 & 68,49 \\
\hline
\end{tabular}

If there is data $\left(D_{i}, H_{i}\right)$ for $i=0,1, \ldots, n$ such that $D_{0}<D_{1}<\ldots<D_{n}$, then there is a unique cubic interpolation splines $S(D)=\operatorname{Si}(D)$ defined by the form: [6]

$$
S_{i}(D)=a_{i-1}+b_{i-1}\left(D-D_{i-1}\right)+c_{i-1}\left(D-D_{i-1}\right)^{2}+d_{i-1}\left(D-D_{i-1}\right)^{3}
$$

Where $a_{i-1}=H_{i-1}$, and the other constants are defined by the forms:

$$
\begin{aligned}
& b_{i-1}=\frac{H_{i}-H_{i-1}}{h_{i}}-\frac{h_{i}}{3}\left(c_{i}+2 c_{i-1}\right) \\
& h_{i} \cdot c_{i-1}+2\left(h_{i}+h_{i+1}\right) c_{i}+h_{i+1} \cdot c_{i+1}=\frac{3\left(H_{i+1}-H_{i}\right)}{h_{i+1}}-\frac{3\left(H_{i}-H_{i-1}\right)}{h_{i}} \\
& d_{i-1}=\frac{c_{i}-c_{i-1}}{3 h_{i}} \\
& h_{1}=141,0-96,8=44,2 ; \quad h_{2}=176,2-141,0=35,2 ; \quad h_{3}=220,4-176,2=44,2 ; \quad c_{0}=c_{3}=0
\end{aligned}
$$

From the form (11), by adding known values, we obtain:

$$
\begin{aligned}
158,8 c_{1}+35,2 c_{2} & =7,14 \\
35,2 c_{1}+158,8 c_{2} & =0,94,
\end{aligned}
$$


Савремена достигнућа у грађевинарству 23-24. април 2019. Суботица, СРБИЈА

and by solving the above-described linear equations system we obtain the coefficients:

$c_{1}=0,044$ i $c_{2}=0,0042$,

and by solving the above-described linear equations system we obtain the coefficients:

$b_{0}=-2,16 ; \quad b_{1}=-1,508 ; \quad b_{2}=-1,764$,

and from the form (12) we get the values of the coefficients:

$d_{0}=0,00033 ; \quad d_{1}=-0,000376 ; \quad d_{2}=-0,0000317$

By adding the calculated values of the coefficients to the form (9), we obtain a family of functions $S(D)$ defined by the form:

$\mathrm{S}(\mathrm{D})=\left\{\begin{array}{cl}3,46 \cdot 10^{-4} \cdot D^{3}-0,10 \cdot D^{2}+6,25 \cdot D+235,5 & D=(96,8 ; 141) \\ -4,75 \cdot 10^{-4} \cdot D^{3}+0,25 \cdot D^{2}-42,72 \cdot D+2537,1 & D=(141 ; 176,2) \\ 3,20 \cdot 10^{-5} \cdot D^{3}-0,02 \cdot D^{2}+4,48 \cdot D-235,3 & D=(176,2 ; 220,4)\end{array}\right.$

Using the spline interpolation, it is formed a family of functions $S(D)$. Each function $S(D)$ is defined by third-order polynomials, which are defined at individual intervals. The interpolated spline function is shown in red (Figure 1). In the same diagram, the real, explicitly expressed function $H=f(D)$ is also shown in blue. It is possible to estimate their matching from the picture. 
Contemporary achievements in civil engineering 23-24. April 2019. Subotica, SERBIA

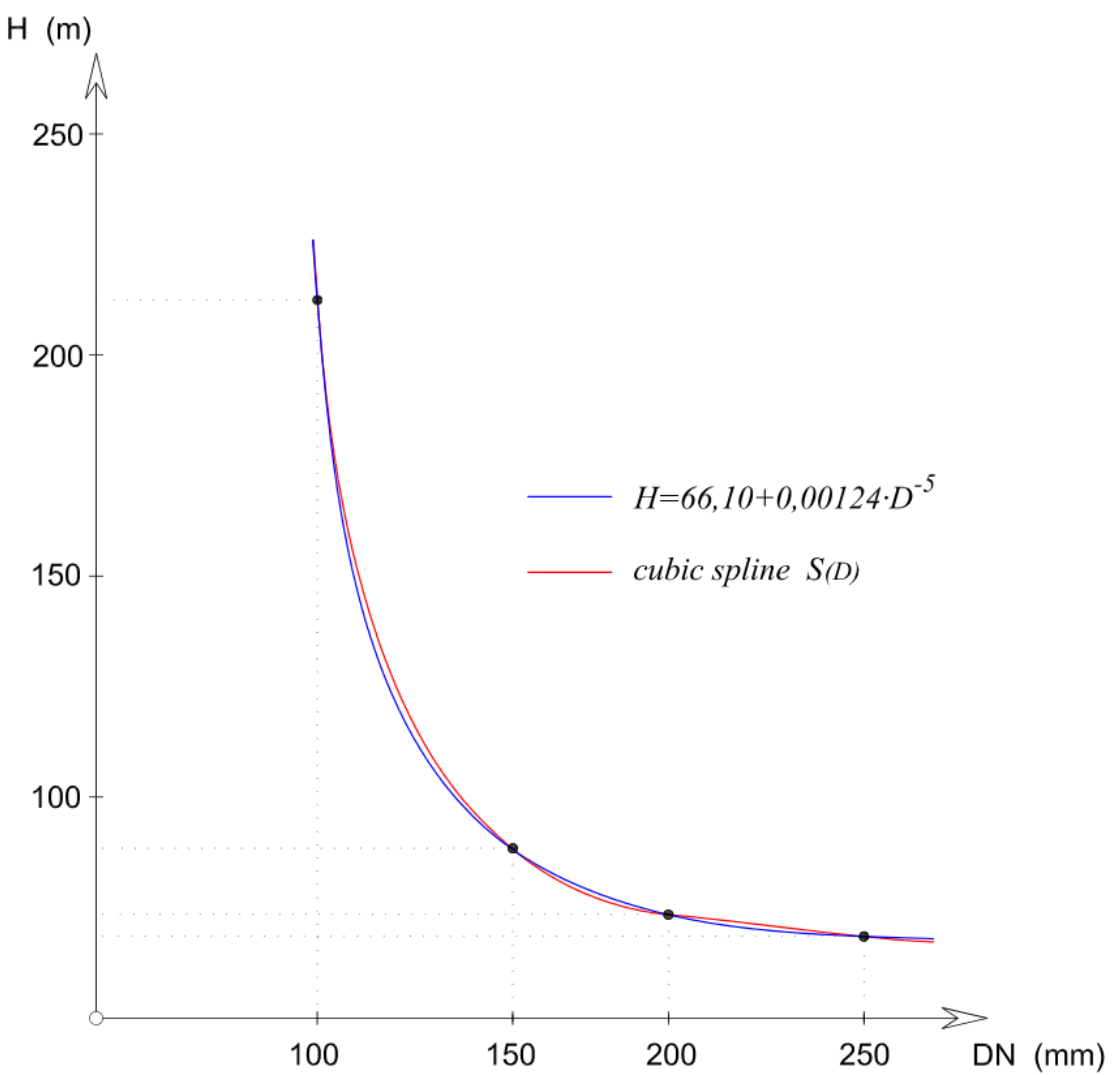

Figure 1: The explicit and interpolated function $H=f(D)$

\section{CONCLUSIONS}

In the planning and construction of water supply systems, considerable attention should be paid to the rationalization of all elements of the system in order to achieve optimum solution from a technical and economic aspect.

When we talk about the sections of the pressure pipeline within the water supply system, one of the key parameters is the adoption of an optimal pipeline diameter. It is known that by reducing the diameter of the pipe, the speed of water flow increases and, consequently, the losses of pressure, which leads to an increase in the cost of pumping water (higher manometer height). The limit of the speed of water in the pipes as well as the initial costs of building the system must certainly be introduced here.

In this paper, using the known forms in hydraulics, the functional dependence of the overall manometric height and pipe diameter for the pushed pipeline section is defined, which is shown in the form (8). Also, for the values of variable D (pipeline diameter), the corresponding values of the total pressure are calculated (Table 1). Based on the data in Table 1, a numerically calculated and constructed spline function is also defined, which also approaches the relationship between the pressure and the diameter of the pipe. 
Савремена достигнућа у грађевинарству 23-24. април 2019. Суботица, СРБИЈА

In this way, two curves were obtained. The first is the explicitly expressed dependence of the above parameters, and the other is the curve obtained by the application of the spline of interpolation, which should be an approximate solution. By overlapping and comparing these two curves (Figure 1), it can be clearly seen that the "spline" function almost identically describes the actual behavior and principles of hydraulics, and that the differences of the spline function and the real function are very small.

Spline interpolation is particularly important in situations where it is impossible (or very complex) to explicitly define the dependence of certain parameters in hydraulics (flow in pipes with variable, irregular cross-section along the pipe, natural watercourses with irregular troughs, etc.). Spline interpolation can have significant application in an experimental hydraulics where, based on the measurements, the mathematical dependence of certain variables can be defined.

A significant advantage of the cubic spline is because by the cubic polynomial can be defined and described most of the natural phenomena as well as the laws of hydraulics. It is clear that the accuracy of spline interpolation is increased by increasing the number of measured data, i.e. which are smaller segments between two known data.

\section{REFERENCES}

[1] Hrnjadović, J.: „Optimization of the pipeline under high hydrostatic pressures in pressure and gravity pipeline in water suply sistem - master thesis“, Faculty of Mining, Geology and Civil Engineering, University of Tuzla, Tuzla 2014.

[2] Ivetić, M.: „Računska hidraulika - tečenje u cevima“, Faculty of Civil Engineering, University of Belgrade, Belgrade, 1996.

[3] Kupusović, T.: „Hidraulika - interna skripta“, Faculty of Civil Engineering Sarajevo, Sarajevo, 2012.

[4] Kupusović, T.: „Mehanika fluida“, IP Svjetlost d.d. Sarajevo, 1998.

[5] Milojević, M.: „Snabdevanje vodom i kanalisanje naselja - šesto izdanje“, Faculty of Civil Engineering, Belgrade, 2003.

[6] Nurkanović, Z., Garić-Demirović, M.: „Odabrana poglavlja matematike“, PrintCom d.o.o., Tuzla 2016.

[7] Suljić, N., Hrnjadović, J.: „Optimization of high preasure pipeline in the pressure pipe of water supply”, Archive for technical sciences, 2017.

[8] Vuković Ž.: “Opskrba vodom i odvodnja I”, Faculty of Civil Engineering, University of Zagreb, Zagreb 2013.

[9] http://matematika.fkit.hr/novo/statistika_i_vjerojatnost/predavanja/, download 19.2.2019. 